\title{
APPLICATION OF ARTIFICIAL NEURAL NETWORK TECHNIQUES FOR PREDICTING THE WATER QUALITY INDEX IN THE PARAKAI LAKE, TAMIL NADU, INDIA
}

\author{
SAHAYA VASANTHI, . $^{1^{*}}-$ AdISH KUMAR, S. $^{2}$ \\ ${ }^{1}$ University College of Engineering Nagercoil, A Constituent College of Anna University \\ Konam, Nagercoil 629004, Tamil Nadu, India \\ ${ }^{2}$ University V O C College of Engineering Tuticorin, A Constituent College of Anna University \\ Tuticorin, Tamil Nadu, India \\ *Corresponding author \\ e-mail: sahaya85@gmail.com; phone: +91-94-8608-3613 \\ (Received $10^{\text {th }}$ Oct 2018; accepted $29^{\text {th }}$ Nov 2018)
}

\begin{abstract}
Nowadays, the demand for forecasting techniques has increased due to conservation management of water resources. In this study, an artificial neural network model (ANN) was followed for determining the water quality index parameters. By the use of computer program, we can get a set of coefficients for a linear model in the calibration of ANN model. The Palayar River is one of the oldest rivers in Tamil Nadu originating from Western Ghats and flowing through Suchinthram area and Parakai Lake. Seven water quality parameters of Parakai Lake were chosen at four monitoring stations in the time period between December 2016 and March 2018. It is clear from the results that the water quality index (WQI) predicted with ANN model brings better output (correlation coefficient $\mathrm{R}=0.9907$ ) when compared with the Multiple regression model having $\mathrm{R}=0.7908$.
\end{abstract}

Keywords: comprehensive pollution index (CPI), multiple linear regression, performance evaluation, water quality

\section{Introduction}

Water is the vital resource for the existence of life. The ultimate use of water for various purposes such as drinking, irrigation and industrial needs has put forth an entire failure in the water quality standards. The excessive use of natural resources has developed a reduction in the water table apart from the significant increase in the concentration of pollutants (Yada et al., 2018). Because of disagreeable conservation management and expansion of population, the water resource has declined and existence of man has become threatened. Water quality indices (WQIs) are widely used to predict the eutrophication levels of lake waters by creating the data interpretation and gathering several parameters of water quality data into one single index. The parameter of all variables of this study is to observe the laboratory analysis and to calculate the pollutants of water body in place of the WQI.

Nowadays, a wide variety of applications of ANN is used to forecast the water quality (Kumar and Sharma, 2015) and to determine the water quality index by the use of independent variables such as DO, COD, BOD, SS, N-NO3 - and pH. By the use of customary water samples, the assessment of water quality and its laboratory analyses is exact, but very costly and more time utilization (Gorashi and Abdullah, 2012). Comprehensive pollution Index for the samples is also calculated. The pollution index method can give an assessable description of water quality which is low, heavy or extremely heavy but it cannot discriminate functional categories of water (Xing, 2011). 
The total dissolved solids, dissolved oxygen and biochemical oxygen demands are forecasted using $\mathrm{pH}$, TS, T-Hard, T-Alk, $\mathrm{K}+, \mathrm{Cl}-, \mathrm{PO}_{4}-, \mathrm{Na}+, \mathrm{N}_{-} \mathrm{NO}_{3}-, \mathrm{N}_{-} \mathrm{NH}_{4}+$, and COD was done by means of a multi-layer perceptron neural network (Maier and Graeme Dandy, 1996). Similarly, Abyaneh (2014) employed the ANN model to forecast DO and BOD. Since the beginning of the 1990s, the applications of ANNs report was created by the areas of environmental sciences, ecological sciences and water engineering (Zali et al., 2011). The proposed model employed artificial neural networks (ANNs) with the back-propagation algorithm which can obtain a highly nonlinear relationship (Chine et al., 2009). The ANN model is constructed for fast calculation and predicting the selected water quality variables at any location. At other locations, particular remaining variables are used as the input parameters such are salinity, temperature, dissolved oxygen, and chlorophyll-alpha (Najah et al., 2013). The application of artificial neural network (ANN) models to simulate water quality parameters is cost-effective, quick, and reliable. This study provides two methods of mathematical and ANN modeling to simulate and forecast five important river water quality indicators (DO, TDS, SAR, $\mathrm{BOD}_{5}, \mathrm{HCO}_{3}$ ) correlated with variables such as EC, temperature, and $\mathrm{pH}$ which can be measured easily and almost with no cost (Salami et al., 2016; Spitz et al., 1999). The WQI is predicted by a simulative model using an ANN. This model has been developed for the assessment of the WQI and compared with the conventionally determined values of WQI. A Multilayer-Perceptron (MLP) network with a single hidden layer was used along with back-propagation algorithm. The results were found to be quite impressive. Thus, the ANN proved to be an efficient tool to assess the WQI of any sample (Hore et al., 2008). The most ordinarily used feed forward error back propagation neural network technique has been utilized. Monthly data sets on turbidity, total hardness, total dissolved solids, and electrical conductivity have been employed for the analysis. The results present the ability of suitable ANN models to predict the water quality parameters (Dawood et al., 2016). The Karoon River in Iran is selected to evaluate the capability of ANNs for water quality simulation. Several water quality variables including $\mathrm{CO}_{3}, \mathrm{HCO}_{3}, \mathrm{SO}_{4}, \mathrm{Cl}, \mathrm{Na}, \mathrm{Ca}, \mathrm{Mg}, \mathrm{K}, \mathrm{EC}$, TDS and SAR has been simulated. Qnet 2000 ANN is selected for modeling purposes in the present research. Results show that Qnet 2000 is able to predict the water quality variables of the Karoon River very successfully with more than $90 \%$ accuracy (MusaviJahromi et al., 2008). The multiple regression models and artificial neural network models are used to predict the value of hardness with respect to the corresponding values of chloride, fluoride, and calcium contents of the groundwater sample based on the specific data. Novel techniques such as Artificial Neural Networks (ANNs) can be used to predict the output from the data set with better accuracy than that using Regression technique. This study will trigger DOE to use ANNs in order to predict WQI rather than using conventional method (WQI equation) that is currently being used by DOE. In addition, the ANNs managed to show remarkable prediction performance to predict the WQI in Juru River (Zali et al., 2011).

Many researchers have activated the artificial neural network technique in the satellite data in order to assess the water quality because of the limitations of linear regression methods. So, that the effort and computational time requirement can be reduced to develop the ANN water quality model. The main objective of this study is the variation of temporal and spatial surface water quality in the Parakai Lake is predicted by the use of multiple regression analysis and ANN model. 


\section{Materials and methods}

\section{Study area}

The study area, Parakai Lake is Located at $8^{\circ} 09^{\prime} 46.2^{\prime \prime} \mathrm{N} 77^{\circ} 26^{\prime} 59.9^{\prime \prime} \mathrm{E}$ (Fig. 1). Parakai Lake is one of the lakes which fed water to irrigation field in southern parts of Kanyakumari district. The lake is fed by canals derived from Pazhayar River. The bound length of the lake extends to $4 \mathrm{~m}$ and water spread area of $1.684 \mathrm{~km}^{2}$ and has an average storage depth of $3.2 \mathrm{~m}$ with holding capacity of $2.351 \mathrm{~m}^{3}$. Kanyakumari district has four distinct seasons such as southwest monsoon (Jun. to Sep.), the northeast monsoon (Oct. to Dec.), the winter (Jan. and Feb.) and the hot weather (Mar. to May). Parakai Lake is located near the southern tip of India in Kanyakumari district in the state of Tamil Nadu, just to the north of Parakai village and west of the town Suchindram. According to the census, the total population of seven villages and two urban habitations along this river bank was 4, 76, 018. Calculation of water supply based on the 135 LPCD, the total quantity of water consuming in above area was 4, 55, $72,2001 /$ day, and its sewage generation ( $80 \%$ of the consuming water) was 3, 64, 57, 832 1/day. The sewage has been discharged into the Parakai Lake without any treatment. The current study focuses the importance on the environmental and health risks subordinate with the use of lake water mixed with sewage fed from open sewerage in the system tank of Parakai Lake. The coordinates of sampling location are shown in Table 1 .

\section{Sample collection and analysis}

The samples are collected from four locations such as 1) Pazhayar river inlet, 2) sewage water inlet, 3) irrigation channel (sluice gate no.2, outlet) and 4) irrigation channel (sluice gate no.5, outlet) (Fig. 1). The monthly water samples are collected from the four nodes by following the water sampling procedure IS 3025 (Part I) 1987. Totally 64 water samples are tested and analysed for the level of concentration of various parameters which are taken from IS 11624 (1986).

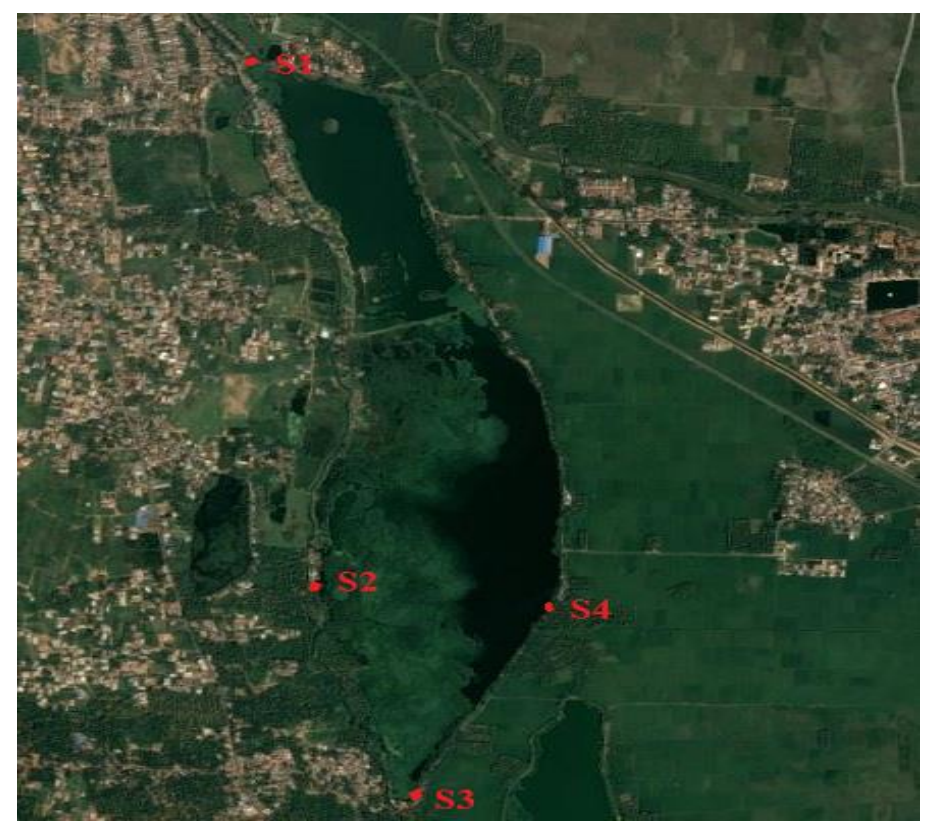

Figure 1. Location of the sampling stations on the Parakai Lake 
Table 1. Water quality sampling stations along Parakai Lake

\begin{tabular}{c|c|c}
\hline \multirow{2}{*}{ Sampling station } & \multicolumn{2}{|c}{ Geographic coordinate } \\
\cline { 2 - 3 } & Latitude & Longitude \\
\hline S1 & $8^{\circ} 16.28^{\prime}$ & $77^{\circ} 44.99^{\prime}$ \\
S2 & $8^{\circ} 14.62^{\prime}$ & $77^{\circ} 45.21^{\prime}$ \\
S3 & $8^{\circ} 14.04^{\prime}$ & $77^{\circ} 45.39^{\prime}$ \\
S4 & $8^{\circ} 14.58^{\prime}$ & $77^{\circ} 45.69^{\prime}$ \\
\hline
\end{tabular}

According to which, the sodium, sodium adsorption ratio, total salt concentration, total dissolved solids, residual sodium carbonate, soluble sodium percentage and boron were considered for improving the water quality criteria for irrigation. The values of concentration are obtained by testing them under suitable conditions and the procedure as given in Table 2 .

Table 2. Water standard specifications given by IS 11624 (1986, reaffirmed 2009) and statistical information of ion concentrations

\begin{tabular}{c|c|c|c|c|c|c}
\hline Sl.No & Parameter & Max. & Min. & Mean & $\begin{array}{c}\text { IS 11624 } \\
\mathbf{( 2 0 0 9 )}\end{array}$ & Analytical method \\
\hline 1 & $\begin{array}{c}\text { Total salt concentration } \\
(\mu \mathrm{s} / \mathrm{cm})\end{array}$ & 405 & 129 & 228.125 & 750 & $\begin{array}{c}\text { Electrometric } \\
\text { conductivity meter }\end{array}$ \\
\hline 2 & $\begin{array}{c}\text { Total dissolved solids } \\
(\mathrm{mg} / \mathrm{l})\end{array}$ & 520 & 195 & 329.813 & 1300 & $\begin{array}{c}\text { Filtration and } \\
\text { gravimetric }\end{array}$ \\
\hline 3 & Sodium (mg/l) & 72 & 14 & 37.5625 & 215 & Flame photometer \\
\hline 4 & $\begin{array}{c}\text { Sodium soluble } \\
\text { percentage }(\%)\end{array}$ & 72.7 & 44.1 & 58.3175 & 60 & By calculation \\
\hline 5 & $\begin{array}{c}\text { Sodium absorption } \\
\text { ratio (mg/l) }\end{array}$ & 17.23 & 3.75 & 10.2081 & 7 & By calculation \\
\hline 7 & $\begin{array}{c}\text { Residual sodium } \\
\text { carbonate (mg/l) }\end{array}$ & 149.49 & 21.52 & 58.785 & 58 & By calculation \\
\hline & Boron (mg/l) & 1.52 & 0 & 0.42157 & 4 & $\begin{array}{c}\text { Annex H of IS 13428 } \\
\text { 4500- B B, APHA 22 } \\
\text { Edition 2012 }\end{array}$ \\
\hline
\end{tabular}

\section{Comprehensive pollution index (CPI)}

Based on the assessment of single factor index and considering the combined effect of all factors evaluated, CPI was calculated through different mathematical models and determines the pollution degrees by the appropriate method (Eqs. 1 and 2).

$$
\begin{gathered}
C P I=\frac{1}{n} \sum_{i=1}^{n} \mathrm{PI} \\
P I=\frac{\text { measured value of individual parameter }}{\text { standard permissible value of parameter }}
\end{gathered}
$$

The CPI values of each sample are calculated and are analyzed by the use of limits stated in Table 3. 
Table 3. CPI limits for water quality

\begin{tabular}{c|c|c}
\hline SI.No & CPI Limits & Category \\
\hline 1 & $<0.2$ & Clean water \\
2 & $0.2-0.4$ & Moderately polluted \\
3 & $0.4-0.6$ & Severely polluted \\
4 & $>0.6$ & Purely sewage water \\
\hline
\end{tabular}

\section{Modeling method}

\section{Multiple linear regressions}

Multiple linear regressions (MLR) were functional as well in this work to validate the relationship between the water quality parameters and their impact on WQI. An MLR model takes the form (Eq. 3):

$$
Y=\beta_{p}+\beta_{1} x_{1}+\beta_{2} x_{2}+\ldots+\beta_{p-1} x_{p-1}+\varepsilon
$$

where $Y$ is the response variable, and there are $p-1$ explanatory variable $x_{1}, x_{2}, \ldots, x_{p-1}$, with $\mathrm{p}$ parameters (regression coefficients) $\beta_{0}, \beta_{1}, \beta_{2}, \ldots, \beta_{p-1}$

In this study the adjusted $\mathrm{R}^{2}$ value was calculated. This adjusted value indicates the loss of predictive power or shrinkage. While $\mathrm{R}^{2}$ explains how much of the variance in $Y$ is accounted for by the regression model, the adjusted value tells us how much variance in $Y$ would be accounted for if the model is derived from the population from which the sample was taken. One version of $\mathrm{R}^{2}$ that explains how well the models cross-validates is the Stein's formula below (Eq. 4):

$$
\text { adjusted } R^{2}=1-\left[\left(\frac{n-1}{n-k-1}\right)\left(\frac{n-2}{n-k-2}\right)\left(\frac{n+1}{n}\right)\right]\left(1-R^{2}\right)
$$

In Stein's equation, $R^{2}$ is the adjusted value, $n$ is the number of subjects and $k$ is the number of predictors in the model. It is useful to use the equation to cross validate a regression model.

\section{Artificial neural network as WQI prediction model}

In the Artificial Neural Network model, an output layer is water quality index and it is used according to the Indian standard. Here, the input variables are collected based on the correlation analysis. Based on the priority target, the forecaster variables are selected and separated where parameters can be analyzed in the field. The initial predictors contained seven parameters of water quality.

\section{Pre-processing of data}

The original testing sample data are collected and these data are converted into 64 segments such as 40 data are used for training and remaining 24 are used for testing. The net architecture for WQI comprises of input nodes and output node. The desired 
output delivered by the choices of input parameters used. In the present study, the input variables are sodium, soluble sodium percentage, sodium adsorption ratio, total salt concentration, total dissolved solids, residual sodium carbonate, and boron. The nonlinear mapping structure comprises of natural networks of biological neurons in brain. It also contains simple calculated units called neurons. These are highly interrelated.

\section{Progress of ANN model}

This model is a multilayer ANNs and assembled with layers of units. The first layer is called as input units and the last layer is known as output units. In the statistical nomenclature the units are known as dependent variables or response variables and the arithmetical input units are called as independent variables remaining other units are called as hidden units and it having hidden layers. There are three basic layers or levels of data processing units viz., the input layer, the hidden layer and the output layer. Each of these layers consists of processing units called nodes of the neural network. The interconnections between the nodes of different layers are called weights of the neural network. These weights are updated or modified iteratively using the generalized delta rule or the steepest gradient descent principle (ASCE Task Committee, 2000). In the present study; the feed forward error back propagation algorithm (Rumelhart et al., 1986) is used for ANN training. Among most of the ANN applications studied in the literature, the feed forward error back propagation neural network is the most popular and widely used ANN architecture. The ANN network used for the present study is shown in Figure 2.

\section{Training of ANN}

An ANN stores the knowledge about the problem in terms of weights of interconnections. The process of determining ANN weight is called learning or training. At the beginning of training, the initial value of weights can be assigned randomly or based on experience. The weights are systematically changed by the learning algorithm such that for a given input, the difference between the ANN output and the actual output is small. Many learning examples are repeatedly presented to the network, and the process is terminated when this difference is less than a specified value. At this stage, the ANN is considered trained. An ANN is better trained as more input data are used.

\section{Performance evaluation}

A large number of statistical criteria are available to compare the goodness/adequacy of any given model. The performance evaluation statistics used for ANN training in the present work are root mean square error (RMSE) and coefficient of correlation (R).

Some statistical analysis techniques are used to validate the result of prediction models. The root mean square error is used to measure the difference between actual value of water quality index and the value from prediction model (Eq. 5).

$$
\boldsymbol{R M S E}=\sqrt{\frac{\sum_{i=1}^{n}\left(W Q I_{\text {act }}-W Q I_{P r e}\right)_{i}^{2}}{n}}
$$

where $\mathrm{WQI}_{\mathrm{act}}=$ actual value of water quality index

$\mathrm{WQI}_{\text {Pre }}=$ predicted value of water quality index

$\mathrm{n}=$ number of monitoring data 


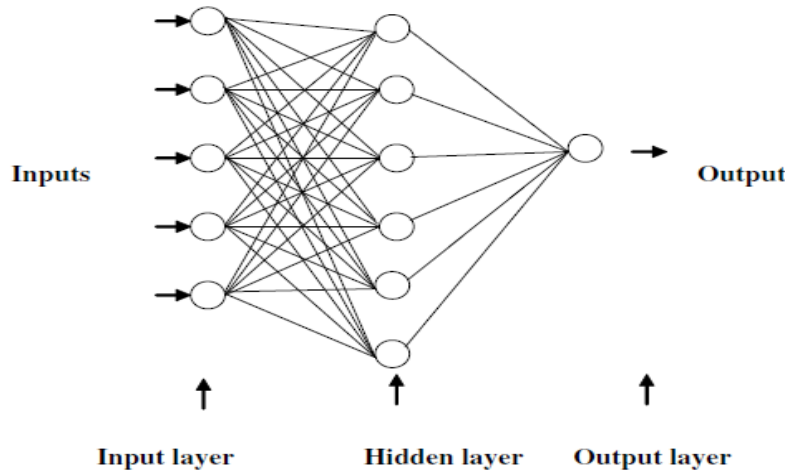

Figure 2. Structure of a multi-layer feed forward artificial neural network model

\section{Results and discussion}

\section{Correlation between the water quality parameters}

From the measured water quality parameters the Pearson's correlation matrix was drawn to find the possible causes of water pollution (Tyagi et al., 2013). The correlation coefficient of seven water quality parameters are categorized by choosing the bivariate significance level 0.05 and 0.01 (Table 4). EC has significant positive correlation with TDS $(r=0.6952)$, sodium $(r=0.8373)$, SSP $(r=0.6733)$, SAR $(r=0.6991)$, RSR $(r=$ 0.5765) and Boron (0.3379). It is observed that with increase or decrease in values of EC; TDS, Na, SSP, SAR, boron also exhibit decrease or increase in their values. It has been expressed that the increasing EC appear to be associated with the increasing use of alkaline detergents in residential areas effluent. TDS has significant positive correlation with sodium $(r=0.8498)$, SSP $(r=0.8215)$, SAR $(r=0.7916)$, RSR $(r=0.5621)$ and Boron (0.6519). This also shows that with increase or decrease in the values of TDS; $\mathrm{Na}, \mathrm{SSP}, \mathrm{SAR}$, boron also show decrease or increase in their values. A significant positive correlation was found between $\mathrm{Na}$ and SSP $(r=0.9269)$, SAR $(r=0.9291)$, RSR $(r=0.7742)$ and boron $(r=0.7142)$. Further, study of boron $(r=0.7817)$ showed a positive correlation with sodium and therefore it can be assumed that $\mathrm{B}$ and $\mathrm{Na}$ originates from the same minerals, most likely from clay.

Table 4. Correlation coefficient of water quality parameters

\begin{tabular}{c|c|c|c|c|c|c|c}
\hline & $\begin{array}{c}\text { Total salt } \\
\text { concentration }\end{array}$ & $\begin{array}{c}\text { Total } \\
\text { dissolved } \\
\text { solids }\end{array}$ & Sodium & $\begin{array}{c}\text { Sodium } \\
\text { soluble } \\
\text { percentage }\end{array}$ & $\begin{array}{c}\text { Sodium } \\
\text { absorption } \\
\text { ratio }\end{array}$ & $\begin{array}{c}\text { Residual } \\
\text { sodium } \\
\text { ratio }\end{array}$ & Boron \\
\hline $\begin{array}{c}\text { Total salt } \\
\text { concentration }\end{array}$ & 1 & & & & & & \\
\hline $\begin{array}{c}\text { Total dissolved } \\
\text { solids }\end{array}$ & 0.6952 & 1 & & & & & \\
\hline Sodium & 0.8373 & 0.8498 & 1 & & & & \\
\hline $\begin{array}{c}\text { Sodium soluble } \\
\text { percentage }\end{array}$ & 0.6733 & 0.8215 & 0.9269 & 1 & & & \\
\hline $\begin{array}{c}\text { Sodium } \\
\text { absorption ratio }\end{array}$ & 0.6991 & 0.7916 & 0.9291 & 0.9905 & 1 & & \\
\hline $\begin{array}{c}\text { Residual sodium } \\
\text { carbonate }\end{array}$ & 0.5765 & 0.5621 & 0.7742 & 0.8348 & 0.8642 & 1 & \\
\hline Boron & 0.3379 & 0.6519 & 0.7142 & 0.7817 & 0.7803 & 0.7444 & 1 \\
\hline
\end{tabular}




\section{Summary of regression model}

The main objective of this work is to reduce the number of parameters needed to carry out the water quality prediction without much loss of information. To meet this objective, MLR is engaged to investigate the connection between the water quality parameters and the dependent variables (WQI). In Equation 3, four variables are meet the entry requirement and which is accounted for approximately $71 \%$ of the variance in WQI. Two variables did not meet the entry requirement, namely the EC and SSP, which is contributed only $8 \%$ and $2 \%$, respectively. The multiple regression coefficient $\mathrm{R}$ is determined between the independent variables and the dependent variables.

The difference between the adjusted $R^{2}$ from the $R^{2}$ was only $7.5 \%(0.625-0.550)$ and the value of regression coefficient $R=0.7908$. This shrinkage means that if the models were derived from December 2016 rather than a sample it would account for approximately $0.7 \%$ less variance in the outcome.

To gain clearer evidence, Stein's formula was applied to $R^{2}(E q .4)$ and it can be applied by replacing $n$ with the sample size and $k$ with the number of predictors. An adjusted $\mathrm{R}^{2}$ is calculated and the value is equal to 0.6084 indicate that the cross-validity of this model is very good (Table 5).

Table 5. Consequences of establishing prediction models

\begin{tabular}{c|c|c|c|c|c|c|c|c}
\hline Model & $\mathbf{R}$ & R-square & $\begin{array}{c}\text { Adjusted } \\
\text { R-square }\end{array}$ & $\begin{array}{c}\text { Standard } \\
\text { error }\end{array}$ & Observations & $\begin{array}{c}\text { Intercept } \\
\text { nodes }\end{array}$ & $\boldsymbol{t}$ Stat & $\boldsymbol{P}$-value \\
\hline 1 & 0.428398 & 0.183525 & 0.02023 & 18.01 & 7 & $\mathrm{~S} 1$ & 2.335601574 & 0.066744 \\
2 & 0.790836 & 0.625421 & 0.550506 & 11.4 & 7 & $\mathrm{~S} 2$ & -0.541583643 & 0.611356 \\
3 & 0.662754 & 0.439243 & 0.327092 & 5.01 & 7 & $\mathrm{~S} 3$ & 2.775151086 & 0.039126 \\
4 & 0.583011 & 0.339902 & 0.207883 & 4.85 & 7 & $\mathrm{~S} 4$ & 2.099131502 & 0.089852 \\
\hline
\end{tabular}

The model can be written in the following form (Eq. 6):

$$
\begin{aligned}
W Q I= & -338.127+1.50764 \mathrm{EC}+0.741 \mathrm{TDS}+7.082 \mathrm{Na} \\
& +6.678 \mathrm{SSP}-41.474 \mathrm{SAR}+1.698 \mathrm{RSC}-36.759 \mathrm{~B}
\end{aligned}
$$

A positive value indicates that, there is a positive relationship between predictor and the outcome whereas a negative coefficient represents a negative relationship. In this study two out of four predictors have negative $\beta$ values. It is clear that when WQI decreases, the pollutant concentration in S1 and S4 decreases. Positive $\beta$ values in S2 and S3 shows an increase of WQI values which is followed by the increase of pollution.

\section{Predicting models for water quality index}

In the neural network prediction model, 40 set of data are used for training and remaining 24 set of data are used for testing. Initially, the model was trained with the selected input and output variables under 8 numbers of neurons. After that the testing was performed by the use of remaining dataset. In order to obtain the accuracy of this model, the length of data sets and number of neurons are changed. The numbers of trials were performed when the value of correlation coefficient is high. This model stimulated the water quality index with great accuracy and the coefficient of correlation $\mathrm{R}$ is 0.9907 (Fig. 3). Numbers of observing data were used in Equation 5 and received the 
root mean square value (RMSE) as 0.00617 . The variations of original and predicted value of pollution index for all locations were identified.
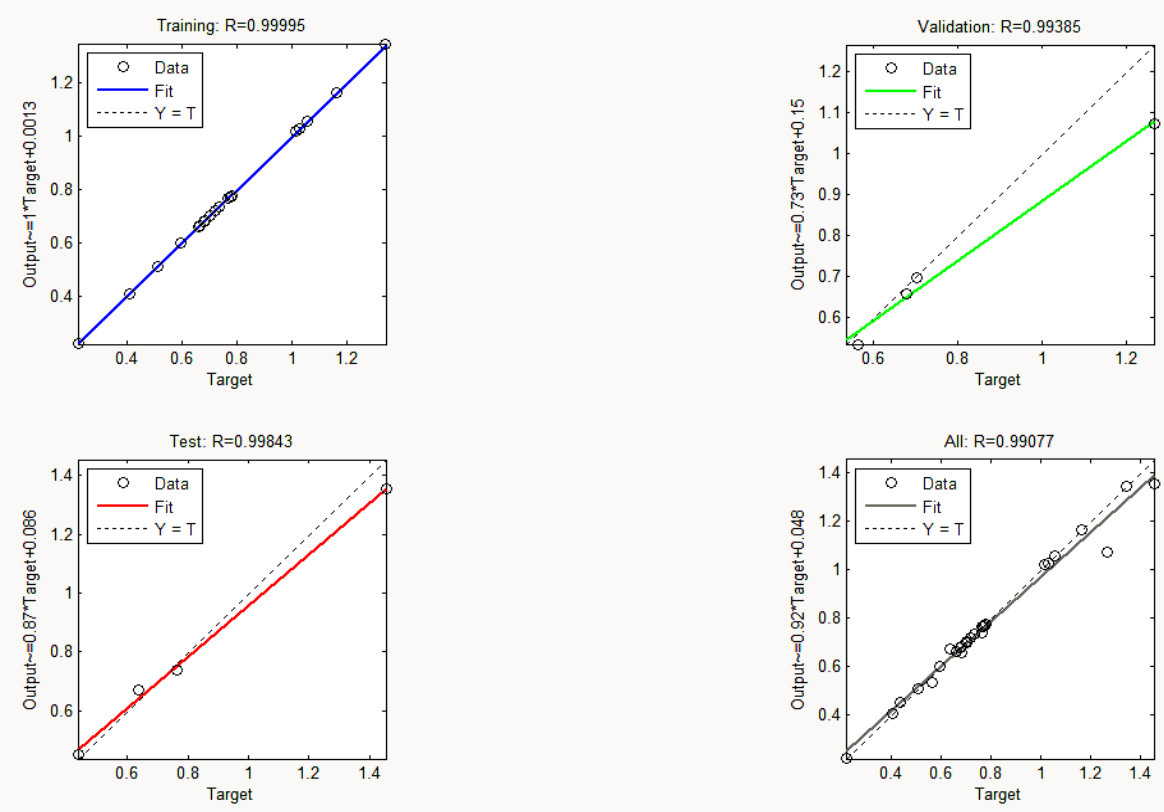

Figure 3. Evaluation models for WQI for recurrent neural network

It was detected (Fig. 4) that the range of CPI for inlet river water is under qualified category (CPI < 0.2) during December 2016 - March 2018. In the same way, the inlet river waste water, the parameters such as residual sodium carbonate and boron fall under severely polluted condition (CPI $>2$ ) due to the flooding of waste water from the surroundings (Fig. 5). For outlet river waters S3 and S4, the parameters EC, TDS, Na and boron fall under qualified category $(\mathrm{CPI}<0.8)$, the parameters such as SSP, SAR and RSC are affected moderately (Figs. 6 and 7). The CPI value of each samples are calculated and are analyzed by the use of limits from Table 3. Based on these limits, we can identify the CPI value of sample 1 as 0.3126 indicates moderately polluted, sample 2 is 0.8789 indicates purely sewage water and sample 3 and 4 is 0.5468 and 0.5428 respectively indicates moderately polluted.

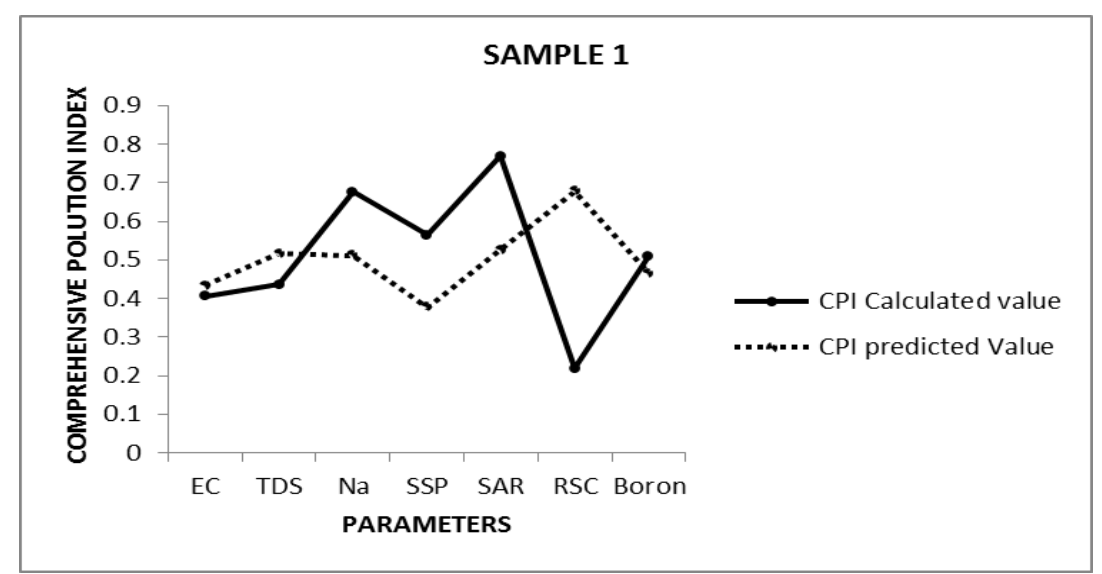

Figure 4. Deviations in comprehensive pollution index for inlet river water 


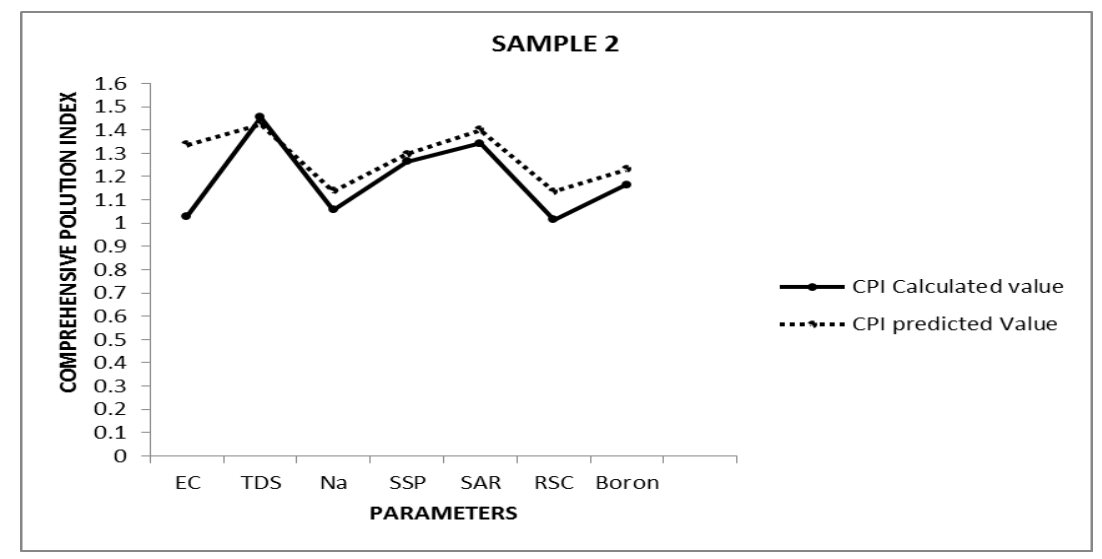

Figure 5. Deviations in comprehensive pollution index for inlet waste water

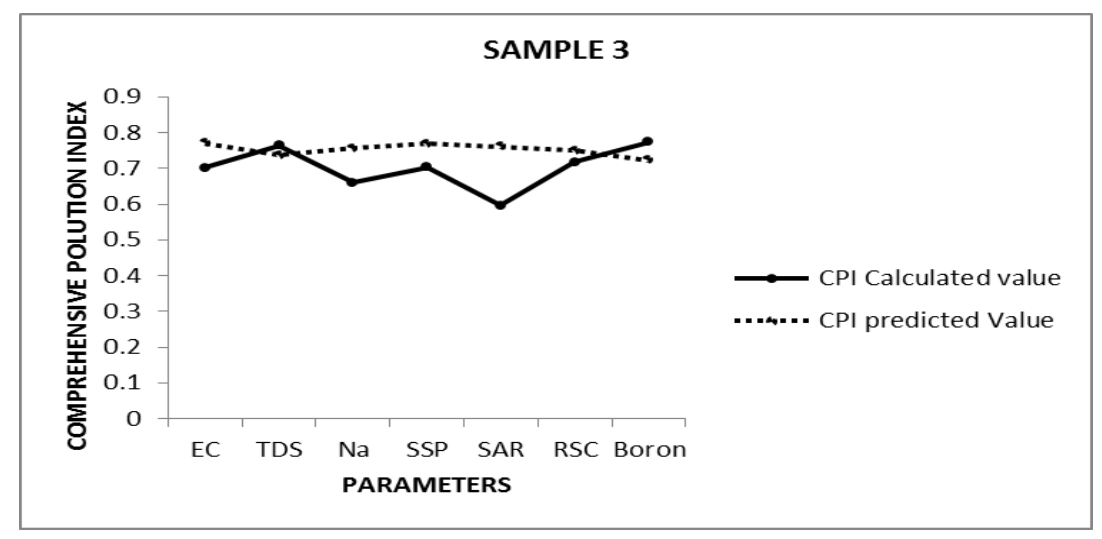

Figure 6. Deviations of comprehensive pollution index for outlet river water

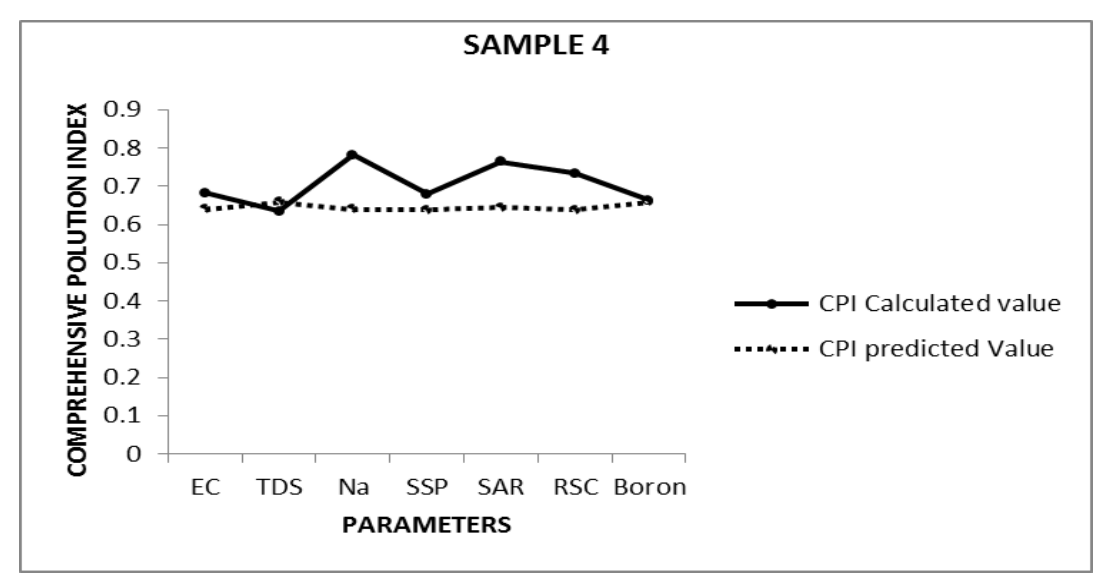

Figure 7. Deviations of comprehensive pollution index for outlet river water

The study proves that, in the ANN model, the coefficient of correlation $(\mathrm{R}=0.9907)$ value is higher than the MLR model $(\mathrm{R}=0.7908)$. Also, the MLR models are statistically significant; they contains higher errors than the ANN models. The results indicate that the ANN model is the wonderful prediction model compared with MLR model. 


\section{Conclusions}

The lake water outlet during the study period revealed that the water is suitable for Irrigation purpose. The measured water quality values are compared with the IS water quality standards of drinking water and it is found that the water is moderately polluted i.e. not suitable for drinking and other life supporting activities, but can be used for irrigation purposes. It is also clear that the increased concentration of sodium may be the root cause for the increase in pollution. Hence, it is summarized that the control of point source and non-point source pollution directly discharged into the lake and are vital to clean the Parakai Lake. From the study, it is understood that the ANN model predicts the water quality indices more accurately than the MLR and also ANN model is a wonderful realistic and forecasting tool. The ANN models explained outstandingly data as long span patterns and as long as good forecasting results.

\section{REFERENCES}

[1] Abyaneh, H. Z. (2014): Evaluation of multivariate linear regression and artificial neural networks in prediction of water quality parameters. - Journal of Environmental Health Science \& Engineering 12(40): 1-8.

[2] Ahmad, Z., Rahim, N. A., Bahadori, A., Zhang, J. (2017): Improving water quality index prediction in Perak river basin Malaysia through a combination of multiple neural networks. - International Journal of River Basin Management 15(1): 79-87.

[3] Dawood, A. S., Hussain, H. K., Hassan, A. (2016): Modeling of river water quality parameters using artificial neural network: a case study. - Proceeding of $40^{\text {th }}$ ISERD International conference, Cairo, Egypt 40: 37-41.

[4] Emamgholizadeh, S., Kashi, H., Marofpoor, I., Zalaghi, E. (2014): Prediction of water quality parameters of Karoon River (Iran) by artificial intelligence - based models. International Journal of Environmental Science Technology 11: 645-656.

[5] Gorashi, F., Abdullah, A. (2012): Prediction of water quality index using back propagation network algorithm. Case study: Gombak River. - Journal of Engineering Science and Technology 7(4): 447-461.

[6] Hore, A., Dutta, S., Datta, S., Bhattacharjee, C. (2008): Application of an artificial neural network in wastewater quality monitoring: prediction of water quality index. International Journal of Nuclear Desalination 3(2). DOI: 10.1504/IJND.2008.020223.

[7] Huo, S., He, Z., Su, J., Xi, B., Zhu, C. (2014): Using artificial neural network models for eutrophication prediction. - International Symposium on Environmental Science and Technology 56(1/2): 63-78.

[8] IS 11624 (1986): Guidelines for the Quality of Irrigation Water. - Bureau of Indian Standards (BIS), Delhi, (R2009).

[9] IS 3025 (1987): Methods of Sampling and Test (Physical and Chemical) for Water and Wastewater. (Part 1). - Bureau of Indian Standards, Delhi.

[10] IS 13428 (2005): Packaged Natural Mineral Water. - Bureau of Indian Standards, Delhi.

[11] Kumar, A., Sharma, M. P. (2015): Assessment of water quality of Ganga river stretch near Koteshwar hydropower station, Uttarakhand, India. - International Journal of Mechanical and Production Engineering 3(8): 82-85.

[12] Li, M., Wu, W., Chen, B., Guan, L., Wu, Y. (2017): Water quality evaluation using back propagation artificial neural network based on self-adaptive particle swarm optimization algorithm and chaos theory. - Computational Water, Energy, and Environmental Engineering 6: 229-242. 
[13] Maier, H. R., Graeme Dandy, C. (1996): The use of artificial neural networks for the prediction of water quality parameters. - Hydro Geochemistry and Water Chemistry 32(4): 1013-1022.

[14] Musavi-Jahromi, S. H., Golabi, M. (2008): Application of artificial neural networks in the river water quality modeling: Karoon River. - Iran Journal of Applied Sciences 8(12): 2324-2328.

[15] Najah, A., El-Shafie, A., Karim Amr, O. A. (2013): Application of artificial neural networks for water quality prediction. - Neural Computing and Applications 22(1): 187201.

[16] Rumelhart, D. E., Hinton, G. E., Williams, R. J. (1986): Learning internal representations by error propagation. - Learning Internal Representation 8: 319-362.

[17] Salami, E. S., Salari, M., Ehteshami, M., Ghadimi, H., Bidokhti, N. T. (2016): Application of artificial neural networks and mathematical modeling for the prediction of water quality variables (case study: southwest of Iran). - Journal of Desalination and Water Treatment 57(56): 1-12.

[18] Singh, G., Kamal, R. K. (2014): Application of water quality index for assessment of surface water quality status in Goa. - Current World Environment 9(3): 994-1000.

[19] Spitz, F., Lek, S. (1999): Environmental impact prediction using neural network modeling: An example in wild life damage. - Journal of Applied Ecology 36(2): 317-326.

[20] Than, N. H., Ly, C. D., Tat, P. T. (2017): Water quality classification by artificial neural network - A case study of Dong Nai river, Vietnam. - Vietnam Journal of Science and Technology 55(4c): 297-303.

[21] Xing, Z., Fu, Q., and Liu, D. (2011): Water quality evaluation by the fuzzy comprehensive evaluation based on EW method. - Eighth International Conference on Fuzzy Systems and Knowledge Discovery, IEEE China. DOI: 10.1109/FSKD.2011.6019494.

[22] Yada, N. S., Amit Kumar, S., Mishra, S., Singhal, S. (2018): Assessment of water quality using pollution-index in the study stretch of river Chambal, India. - Integrated Research Advances 5(1): 20-25.

[23] Zali, M. A., Retnam, A., Juair, H., Sharifuddin, M. Z. (2011): Sensitivity analysis for water quality index (WQI) prediction for Kinta River. - World Applied Sciences Journal 14: 60-65. 